\title{
Awareness, treatment, and control of major cardiovascular risk factors in a small-scale Italian community: results of a screening campaign
}

This article was published in the following Dove Press journal:

Vascular Health and Risk Management

30 April 2013

Number of times this article has been viewed

\author{
Stefano Omboni' \\ Giorgia Carabelli' \\ Edoardo Ghirardi' \\ Stefano Carugo ${ }^{2}$ \\ 'Italian Institute of Telemedicine \\ and Association for Research \\ and Development of Biomedical \\ Technologies and for Continuing \\ Medical Education (ARSMED), Varese, \\ Italy; ${ }^{2} \mathrm{UOC}$ di Cardiologia, Azienda di \\ Servizi alla Persona Istituti Milanesi \\ Martinitt e Stelline e Pio Albergo \\ Trivulzio, Milano, Italy
}

Introduction: Hypertension, hypercholesterolemia, and diabetes are the main causes of cardiovascular diseases in developed countries. However, these conditions are still poorly recognized and treated.

Objective: This study aimed at estimating the prevalence, awareness, treatment, and control rates of major cardiovascular risk factors in an unselected sample of individuals of a small community located in northern Italy.

Methods: We screened 344 sequential subjects in this study. Data collection included family and clinical history, anthropometric data, blood pressure, blood glucose, and serum cholesterol values. Individual cardiovascular risk profiles were assessed by risk charts of the Progetto Cuore.

Results: Based on personal history and/or measured values, $78.2 \%$ of subjects had hypercholesterolemia (total cholesterol levels $>190 \mathrm{mg} / \mathrm{dL}$ ), $61.0 \%$ had central obesity (waist circumference $\geq 94 \mathrm{~cm}$ for men and $\geq 80 \mathrm{~cm}$ for women), $51.2 \%$ had arterial hypertension (blood pressure $\geq 140 / 90 \mathrm{mmHg}$ ), $8.1 \%$ had diabetes (blood glucose $\geq 126 \mathrm{mg} / \mathrm{dL}$ ), $22.7 \%$ had impaired fasting glucose (blood glucose 100-125 mg/dL), and 35.5\% were overweight (body mass index 25-29 kg/m²). Alcohol drinkers and smokers accounted for $46.2 \%$ and $22.4 \%$ of subjects, respectively. Awareness of hypertension, hypercholesterolemia, and diabetes was poor, and control of these risk factors, except for diabetes, was even worse. Prevalence of high blood pressure, high serum cholesterol, overweight, and obesity significantly increased with aging. Hypercholesterolemia and obesity were significantly more common in women, while overweight and diabetes in men. In $15.4 \%$ of participants, the risk of a major cardiovascular event in the next 10 years was either high or very high.

Conclusion: In a small community in a wealthy region of Italy, the prevalence of major cardiovascular risk factors is high, while awareness, treatment, and control are poor. Such a result highlights the importance of screening campaigns as a strategy to improve early diagnosis and access to treatment, and thus effective prevention of cardiovascular diseases in the general population.

Keywords: hypertension, hypercholesterolemia, diabetes, obesity, cardiovascular risk, Italy

\section{Introduction}

Cardiovascular risk factors, such as high blood pressure, dyslipidemia, diabetes, and obesity are considered a major disease burden and account for a large contribution to global loss of healthy life due to cardiovascular diseases worldwide. ${ }^{1,2}$ It is estimated that in developed countries millions of deaths are annually attributable to cardiovascular disease, but the levels and trends vary from country to country. ${ }^{3-6}$
Correspondence: Stefano Omboni
Italian Institute of Telemedicine

Via Colombera 29, 21048 Solbiate

Arno, Varese, Italy

Tel +39033I 984529

Fax +39033I 984530

Email stefano.omboni@iitelemed.org 
Although age-adjusted cardiovascular death rates declined in most developed countries in the past few decades, ${ }^{3-6}$ the prevalence of underlying risk factors and thus the hazard of cardiovascular disease changed minimally, ${ }^{7-9}$ hence keeping morbidity and mortality rates high. Research efforts in recent years have made available simple methods for early identification of main cardiovascular risk factors and have developed efficient remedies for correcting such abnormalities. Encouragingly, because most of the risk factors for cardiovascular disease, such as hypertension, unfavorable lipid cholesterol profile, obesity, smoking, physical inactivity, and to a lesser extent diabetes, are considered to be largely modifiable, many deaths and disabilities due to cardiovascular disease can be prevented. ${ }^{10,11}$ Cardiovascular disease can be avoided or delayed by combining strategies based on early detection, effective treatment, and healthy lifestyle changes. Indeed, epidemiologic studies and randomized clinical trials have provided compelling evidence that coronary disease is largely preventable by addressing known risk factors. ${ }^{11-13}$

Effective prevention of cardiovascular disease by adequate control of major cardiovascular risk factors can provide substantial and underestimated public health gains. However, improvement of detection and control of major cardiovascular risk factors in the general population continues to be a major challenge, because of poor awareness of an individual's status. A solution to this problem might be more aggressive and early identification and appropriate correction of cardiovascular risk factors through sensitization campaigns, where risk factors can be easily checked and promptly recognized.

The objective of the present investigation was to evaluate the prevalence, awareness, treatment, and control of major cardiovascular risk factors in an unselected population of a small community located in northern Italy. The study was based on a very simple screening program, in order to demonstrate the effectiveness of such an approach for appropriate detection of cardiovascular risk factors.

\section{Methods}

\section{Study design}

This was a community based survey focusing on screening main cardiovascular risk factors in an unselected population. Subjects living in a wide area located North of Milan and South of Varese (Northern Italy, Lombardy region), were invited through advertisements released in pharmacies, general practitioners' offices, or Italian Red Cross local offices, to attend a mobile center to undergo a medical checkup. During the visit, in addition to age and sex, the following information was obtained from each subject: family history for cardiovascular diseases; personal clinical history for associated cardiovascular diseases; presence and treatment of arterial hypertension, diabetes mellitus, and hypercholesterolemia. Subjects were also asked whether they were current cigarette smokers or alcohol drinkers. Following the interview, anthropometric measurements were taken, and blood pressure, serum cholesterol, and blood glucose were measured, as detailed in the next sections. Subjects were asked to fast for 12 hours before the examination to ensure optimal blood test accuracy. They were also allowed to take their prescribed drug treatment, if any.

Prior to the examination, participants were asked to give written informed consent for collection and analysis of their clinical data, according to current Italian law. All visits took place between July and October 2007.

\section{Anthropometric measurements}

Body height, weight, and waist circumference were all taken in a standardized manner. ${ }^{14,15}$ Body weight and height were measured on subjects without shoes and wearing light clothing (underwear, skirt or pants, and a shirt), using a calibrated, professional, electronic scale (Seca GmbH \& Co. Kg., Hamburg, Germany). Waist circumference was determined at minimal respiration by a measuring tape placed around the abdomen at the level of the high point of the iliac crest and kept parallel respect to the ground. In order to ensure accurate measurements, subjects were instructed to gather their shirt above the waist, cross their arms, and place their hands on opposite shoulders.

Body mass index was calculated as weight divided by squared height and expressed as $\mathrm{kg} / \mathrm{m}^{2}$. A body mass index $\geq 30 \mathrm{~kg} / \mathrm{m}^{2}$ was regarded as compatible with obesity. Overweight was defined by a body mass index ranging between $25 \mathrm{~kg} / \mathrm{m}^{2}$ and $29.9 \mathrm{~kg} / \mathrm{m}^{2}$. A waist circumference $\geq 94 \mathrm{~cm}$ in males and $\geq 80 \mathrm{~cm}$ in females was used to define central or abdominal obesity, according to the International Federation of Diabetes Guidelines. ${ }^{16}$

\section{Blood pressure measurement}

Blood pressure was measured according to current recommendations ${ }^{17}$ using a validated, automatic, electronic, upper-arm sphygmomanometer (UA-787, A\&D Company Limited, Tokyo, Japan), ${ }^{18}$ with the patient in the sitting position for 5 minutes before the measurement. The average of two consecutive measurements, spaced by an interval of 2 minutes was considered as the representative blood 
pressure value of the subject. Hypertension was defined by a systolic blood pressure $\geq 140 \mathrm{mmHg}$ and/or a diastolic blood pressure $\geq 90 \mathrm{mmHg}{ }^{19}$

\section{Blood testing}

Following blood pressure measurement, serum total cholesterol, high density lipoprotein cholesterol (HDL), and blood glucose concentrations were measured using the CardioChek PA analyzer (Polymer Technology Systems Inc, Indianapolis, IN, USA). ${ }^{20}$ Blood samples were taken from the index finger. Before the test, the finger was thoroughly cleaned with an alcohol preparation and then lanced on the side to obtain two drops of blood. The first drop was wiped away with a cloth, while the second was used for the test. A capillary was placed under the blood drop in order to allow collection. The drop was then plunged from capillary onto a test strip placed in the analyzer. Results were available within 2 minutes and displayed on the digital screen of the analyzer. Two different strips were used, one for checking total and HDL cholesterol and one for blood glucose. Precision and accuracy of the CardioChek PA analyzer were evaluated and compared in previous validation studies with clinical diagnostic laboratory methods and found to be acceptable. ${ }^{20}$

Metabolic abnormalities were detected in presence of a total cholesterol $>190 \mathrm{mg} / \mathrm{dL}$ (hypercholesterolemia), HDL cholesterol $<40 \mathrm{mg} / \mathrm{dL}$ in males and $<50 \mathrm{mg} / \mathrm{dL}$ in females, and blood glucose $\geq 126 \mathrm{mg} / \mathrm{dL}$ (diabetes). Impaired fasting glucose was defined as a blood glucose ranging between $100 \mathrm{mg} / \mathrm{dL}$ and $125.9 \mathrm{mg} / \mathrm{dL}$. Dyslipidemia was diagnosed in the presence of elevated total cholesterol and/or low HDL cholesterol.

Thresholds for identification of all the aforementioned cardiovascular risk factors were based on indications issued by the European Society of Hypertension and Cardiology, the International Federation of Diabetes and the American Diabetes Association. ${ }^{16,19,21}$

\section{Data analysis}

At the time of the examination, data from each subject were reported on a paper sheet. Individual data were then entered into an electronic database to allow pooled analysis. Patients were considered having hypertension, hypercholesterolemia, or diabetes mellitus on the basis of a previous diagnosis by a general practitioner or a specialist or if they were under specific drug treatment, or on the basis of the measured blood pressure, serum cholesterol, or blood glucose levels.
The degree of individual cardiovascular risk was established according to the Progetto Cuore equation. This is an algorithm derived from and validated in a large Italian cohort of individuals, predicting the risk of fatal and nonfatal major coronary events in the next 10 years. The equation fits together age, sex, systolic blood pressure, total cholesterol, HDL cholesterol, smoking status, and treatment for diabetes or for high blood pressure. ${ }^{22,23}$

The prevalence of the various cardiovascular risk factors was assessed by computing the absolute (n) and relative (\%) frequency of occurrence for the whole sample of subjects, and for subgroups, according to decades of age ( $<40,40-49$, $50-59,60-69$, and $\geq 70$ years) and sex (male or female). Continuous variables were also calculated and expressed as means \pm standard deviation. Differences in percentages were compared using the Chi-square test and differences in means by analysis of variance. A $P$-value $<0.05$ was considered significant.

\section{Results}

A total of 344 subjects were screened and enrolled in this study. Demographic, anthropometric, and clinical data of the participants are presented in Table 1. Mean subject age was 54.9 years, and females were slightly more prevalent than males $(52.6 \%$ versus $47.4 \%)$. A positive family history for hypertension was reported by $38.1 \%$ of subjects, followed in frequency by diabetes $(25.9 \%)$, and premature cardiovascular disease (myocardial infarction [19.2\%] and stroke [6.1\%]). A personal history of cardiovascular disease was recorded in $18.9 \%$ of subjects.

As shown in Figure 1, considering either a previous diagnosis or values measured during the examination (anthropometric data, blood pressure values, and blood tests), the most common cardiovascular risk factors were, in decreasing order, hypercholesterolemia ( $78.2 \%$ of subjects), followed by central obesity (61.0\%), and hypertension (51.2\%). Elevated total cholesterol and/or low HDL cholesterol (dyslipidemia) were reported in the majority of subjects (86.0\%). Current alcohol drinkers and smokers accounted for $46.2 \%$ and $22.4 \%$ of the total sample, respectively. An obese state (body mass index $\geq 30 \mathrm{~kg} / \mathrm{m}^{2}$ ) was observed in $10.2 \%$ of subjects, while overweight (body mass index $\geq 25$ and $<30 \mathrm{~kg} / \mathrm{m}^{2}$ ) was displayed by $35.5 \%$ of subjects. The overall prevalence of diabetes was $8.1 \%$, while impaired fasting glucose was observed in $22.7 \%$ of subjects.

\section{Blood pressure}

Arterial hypertension (systolic blood pressure $\geq 140$ or diastolic blood pressure $\geq 90 \mathrm{mmHg}$ or previous diagnosis) 
Table I Demographic and clinical characteristics of the 344 subjects of the study population

\begin{tabular}{|c|c|}
\hline & $\mathrm{n}=344$ \\
\hline Age (years) & $54.9 \pm 15.1(19-85)$ \\
\hline \multicolumn{2}{|l|}{ Age class (years) } \\
\hline$<40$ & $59(17.2)$ \\
\hline $40-49$ & $67(19.5)$ \\
\hline $50-59$ & $72(20.9)$ \\
\hline $60-69$ & $87(25.3)$ \\
\hline$\geq 70$ & $59(17.2)$ \\
\hline \multicolumn{2}{|l|}{ Sex } \\
\hline Male & $163(47.4)$ \\
\hline Female & $181(52.6)$ \\
\hline Family history for cardiovascular disease & $233(67.7)$ \\
\hline Arterial hypertension & $131(38.1)$ \\
\hline Diabetes & $89(25.9)$ \\
\hline Myocardial infarction & $66(19.2)$ \\
\hline Stroke & $21(6.1)$ \\
\hline Kidney disease & $13(3.8)$ \\
\hline Dyslipidemia & $7(2.0)$ \\
\hline Personal history for cardiovascular disease & $65(18.9)$ \\
\hline Ischemic heart disease & $7(2.0)$ \\
\hline Heart failure & $7(2.0)$ \\
\hline Peripheral artery disease & $7(2.0)$ \\
\hline Kidney disease & $6(1.7)$ \\
\hline Myocardial infarction & $5(1.5)$ \\
\hline Stroke & $2(0.6)$ \\
\hline Height (cm) & $166.1 \pm 8.6(144-190)$ \\
\hline Weight (kg) & $69.4 \pm 13.1(40-170)$ \\
\hline BMI $\left(\mathrm{kg} / \mathrm{m}^{2}\right)$ & $25.1 \pm 4.0(15.1-43.1)$ \\
\hline Waist circumference $(\mathrm{cm})$ & $90.6 \pm 12.2(62-126)$ \\
\hline $\mathrm{SBP}(\mathrm{mmHg})$ & $135.9 \pm 23.0(81.5-235)$ \\
\hline $\mathrm{DBP}(\mathrm{mmHg})$ & $79.7 \pm 1 \mid .3(50.5-|| 4.0)$ \\
\hline Total serum cholesterol (mg/dL) & $220.8 \pm 51.1(100-379)$ \\
\hline HDL serum cholesterol (mg/dL) & $57.5 \pm 17.5(15-100)$ \\
\hline Blood glucose (mg/dL) & $91.8 \pm 21.4(33-192)$ \\
\hline Smoking & $77(22.4)$ \\
\hline Alcohol & $159(46.2)$ \\
\hline
\end{tabular}

Notes: Data are shown as means \pm SD and ranges (in brackets), or as absolute (number) and relative frequencies (percentages).

Abbreviations: BMI, body mass index; DBP, diastolic blood pressure; HDL, high density lipoprotein; SBP, systolic blood pressure; SD, standard deviation.

was present in $51.2 \%$ of subjects, of whom $55.7 \%$ were aware (28.5\% of all subjects) and $44.3 \%$ were not aware $(22.7 \%$ of all subjects) of their condition (Figure 2A). The majority of subjects with hypertension $(92.9 \%)$ were using specific antihypertensive medications, but only $31.9 \%$ of them had controlled blood pressure $(<140 / 90 \mathrm{mmHg}$; Figure $2 \mathrm{~B})$.

\section{Serum cholesterol}

Hypercholesterolemia (total serum cholesterol $>190 \mathrm{mmHg}$ or previous diagnosis) was the most common major cardiovascular risk factor, affecting $78.2 \%$ of the screened subjects: $43.1 \%$ of these individuals (33.7\% of all subjects) were aware of their condition, while $56.9 \%$ were not $(44.5 \%$ of

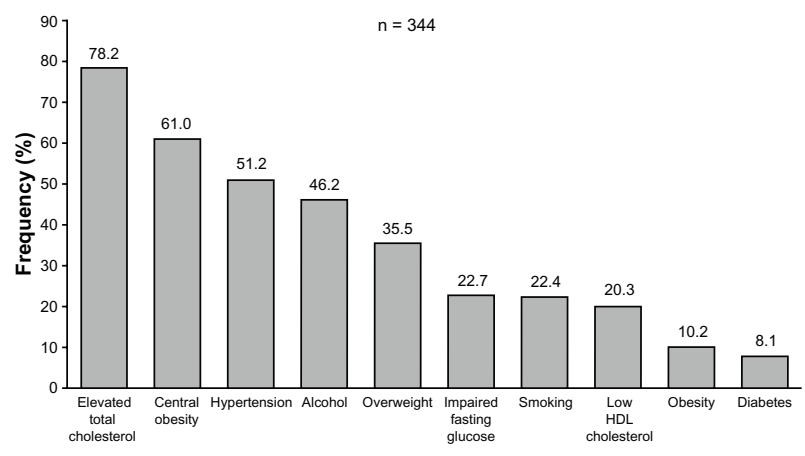

Figure I Prevalence of major cardiovascular risk factors in the 344 subjects of the study.

Note: Data are reported as percentages (\%) of the total number.

Abbreviation: HDL, high density lipoprotein.

all subjects; Figure 2A). Only a limited portion of subjects aware of hypercholesterolemia were on lipid-lowering medication (31.0\%): of these, only $25.0 \%$ had a total serum cholesterol $\leq 190 \mathrm{mg} / \mathrm{dL}$ (Figure 2B).

Low serum HDL cholesterol $(<40 \mathrm{mg} / \mathrm{dL}$ in males and $<50 \mathrm{mg} / \mathrm{dL}$ in females) was observed in $20.3 \%$ of subjects, while dyslipidemia (high total serum cholesterol and/or low HDL cholesterol) was reported in $82.8 \%$ of subjects.

\section{Blood glucose}

Of the examined subjects, $8.1 \%$ had high blood glucose $(\geq 126 \mathrm{mg} / \mathrm{dL})$ or previously diagnosed diabetes, of whom
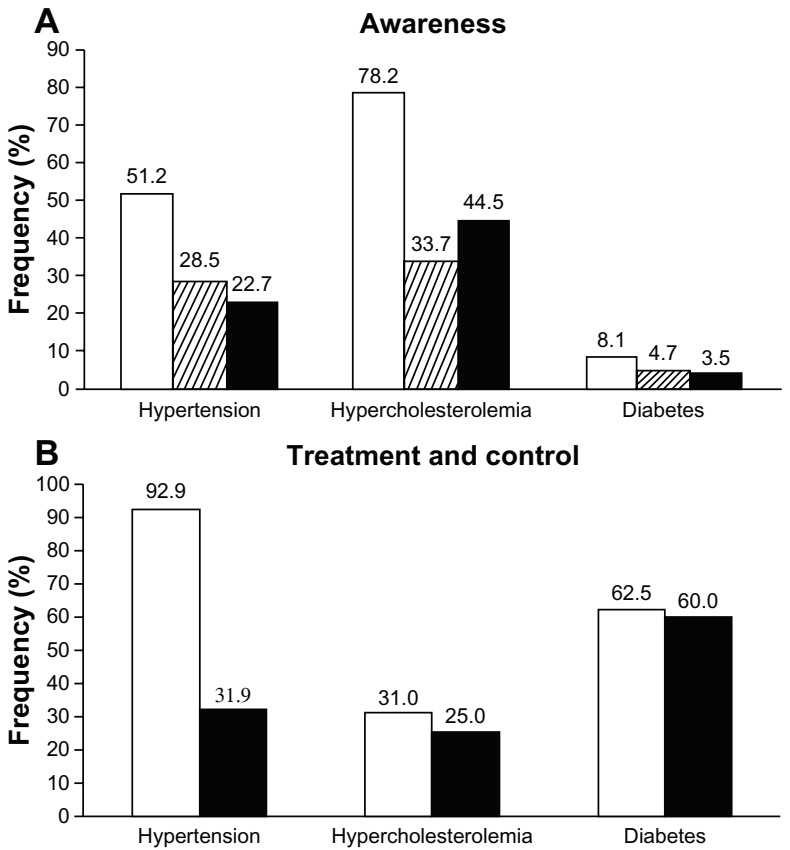

Figure 2 Prevalence (open bars), awareness (striped bars), and lack of awareness (full bars) of hypertension, hypercholesterolemia or diabetes in the 344 subjects of the study (A). Rates of treated (open bars) and of treated and controlled subjects (full bars) are shown in (B).

Note: Data are summarized as percentages (\%). 
$57.1 \%$ were aware (4.7\% of all subjects) and $42.9 \%$ were not aware $(3.5 \%$ of all subjects) of their condition (Figure 2A). Most of the patients with diabetes (62.5\%) were under pharmacological treatment yet still had a blood glucose $<126 \mathrm{mg} / \mathrm{dL}(60.0 \%$; Figure $2 \mathrm{~B})$.

\section{Cardiovascular risk factors and age}

As shown in Figure 3, average values of body mass index, waist circumference, systolic blood pressure, total serum cholesterol, and blood glucose significantly increased and diastolic blood pressure and serum HDL cholesterol significantly decreased with age. Diastolic blood pressure and total and HDL cholesterol values plateaued at advanced age. Prevalence and awareness of hypertension, hypercholesterolemia, and diabetes, as well as percentages of treated subjects increased with age, while control of risk factors was progressively less common from the youngest to the oldest age (Table 2). However, trend analysis revealed a statistically significance increase as a function of age only for prevalence and awareness of high blood pressure and elevated total cholesterol.

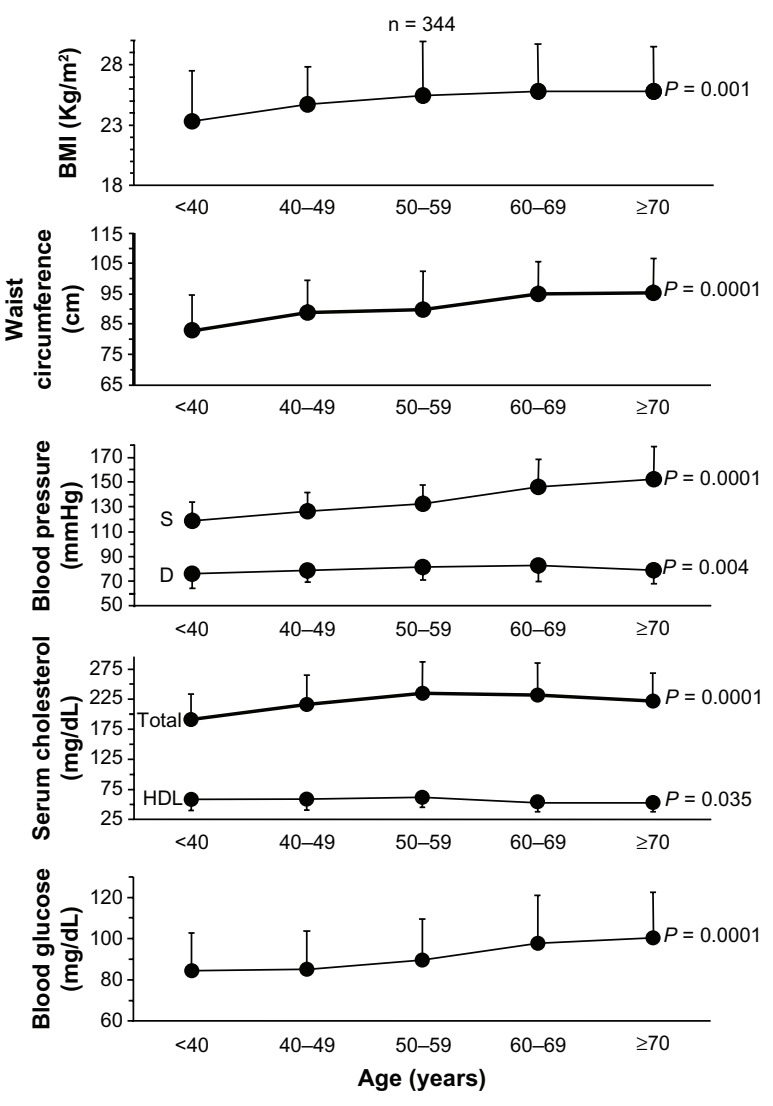

Figure 3 Mean values \pm SD for BMI, waist circumference, $S$ and D blood pressure, total and HDL serum cholesterol and blood glucose in the 344 subjects of the study according to decades of age.

Notes: $P$-values indicate the level of statistical significance for the trend analysis. Abbreviations: BMI, body mass index; D, diastolic; HDL, high density lipoprotein; S, systolic; SD, standard deviation.
Prevalence of impaired fasting glucose increased with age (from $16.9 \%$ for subjects $<40$ years to $32.2 \%$ for subjects $\geq 70$ years, $P=0.053$ ), this also being the case for dyslipidemia (from $66.1 \%$ to $88.1 \%, P=0.006$ ), overweight (from $25.4 \%$ to $45.8 \%, P=0.022$ ), obesity (from $5.1 \%$ to $10.2 \%, P=0.231$ ), and central obesity (from $33.9 \%$ to $81.4 \%, P=0.0001$ ).

\section{Cardiovascular risk factors and sex}

Body mass index, waist circumference, blood pressure, and blood glucose were significantly higher and total cholesterol and HDL cholesterol significantly lower in males compared to females (Figure 4). The prevalence, awareness, treatment, and control of hypertension did not significantly differ among sexes, while hypercholesterolemia was more common in females and diabetes in males.

Impaired fasting glucose was more prevalent in males (23.9\% versus $21.5 \%$ females, $P=0.008)$, this was also the case for overweight ( $44.8 \%$ versus $27.1 \%, P=0.003)$. Conversely, dyslipidemia, obesity, and central obesity were more common in females $(89.0 \%, 11.0 \%$, and $66.9 \%$ versus $76.1 \%, 9.2 \%$, and $54.6 \%$ in males, $P=0.002, P=0.0571$, and $P=0.020$, respectively).

\section{Overall cardiovascular risk}

Cardiovascular risk factors (dyslipidemia, high blood pressure, diabetes or impaired fasting glucose, overweight or obesity, cigarette smoking, and alcohol drinking) tended to be grouped, with $37.8 \%$ of participants displaying 1-2 of such risk factors, $59.9 \% \geq 3$, and $2.3 \%$ none $(P=0.0001)$. When only the four major cardiovascular risk factors (dyslipidemia, hypertension, diabetes, and obesity) were considered, $\geq 3$ of them were recorded in $38.4 \%$ of individuals, $1-2$ in $57.0 \%$, and none in $4.7 \%(P=0.0001)$.

In the whole study population the average \pm standard deviation risk of a major cardiovascular event in the next 10 years was $7.3 \% \pm 10.4 \%$, with $61.9 \%$ of subjects in the low class risk $(<5 \%), 22.7 \%$ in the mid $(5 \%-10 \%), 5.5 \%$ in the high-moderate $(15 \%-20 \%), 5.2 \%$ in the high $(20 \%-30 \%)$, and $4.7 \%$ in the very high $(\geq 30 \%)$ class $(P=0.0001)$. When the 65 subjects with a positive history for a previous cardiovascular disease were excluded from cardiovascular risk estimation, the score averaged to $6.3 \% \pm 9.1 \%$ with $52.9 \%$ of subjects in the low, $17.4 \%$ in the mid, $4.1 \%$ in the high-moderate, $3.8 \%$ in the high, and $2.9 \%$ in the very high risk classes $(P=0.0001)$.

\section{Discussion}

In recent years, the prevalence of hypertension, dyslipidemia, diabetes, and obesity underwent a dramatic increase in 
Table 2 Prevalence, treatment, and control of hypertension, hypercholesterolemia, and diabetes according to age and sex

\begin{tabular}{|c|c|c|c|c|c|c|c|c|}
\hline & $\mathbf{n}$ & Total prevalence & Aware & Not aware & $\mathbf{n}$ & Treated & $\mathbf{n}$ & Controlled \\
\hline \multicolumn{9}{|c|}{ Hypertension } \\
\hline \multicolumn{9}{|c|}{ Age class (years) } \\
\hline$<40$ & 59 & 7 (II.9) & $3(5.1)$ & $4(6.8)$ & 3 & $2(66.7)$ & 2 & - \\
\hline $40-49$ & 67 & $20(29.9)$ & $4(6.0)$ & 16 (23.9) & 4 & $3(75.0)$ & 3 & $2(66.7)$ \\
\hline $50-59$ & 72 & $36(50.0)$ & $16(22.2)$ & $20(27.8)$ & 16 & 14 (87.5) & 14 & $7(50.0)$ \\
\hline $60-69$ & 87 & $64(73.6)$ & $43(49.4)$ & $21(24.1)$ & 43 & $42(97.7)$ & 42 & $10(23.8)$ \\
\hline$\geq 70$ & 59 & $49(83.1)$ & $32(54.2)$ & $17(28.8)$ & 32 & $30(93.8)$ & 30 & $10(33.3)$ \\
\hline$P$-value & & 0.0001 & 0.0001 & 0.027 & & 0.123 & & 0.198 \\
\hline \multicolumn{9}{|l|}{ Sex } \\
\hline Male & 163 & $88(54.0)$ & $47(28.8)$ & $4 \mathrm{I}(25.2)$ & 47 & $44(93.6)$ & 44 & $13(29.5)$ \\
\hline Female & $|8|$ & $88(48.6)$ & $51(28.2)$ & $37(20.4)$ & 51 & 47 (92.2) & 47 & $16(34.0)$ \\
\hline$P$-value & & 0.320 & 0.893 & 0.297 & & 0.779 & & 0.645 \\
\hline \multicolumn{9}{|c|}{ Hypercholesterolemia } \\
\hline \multicolumn{9}{|c|}{ Age class (years) } \\
\hline$<40$ & 59 & $30(50.8)$ & $6(10.2)$ & $24(40.7)$ & 6 & I (I6.7) & 1 & - \\
\hline $40-49$ & 67 & $52(77.6)$ & $21(3 \mid .3)$ & $31(46.3)$ & 21 & $3(14.3)$ & 3 & - \\
\hline $50-59$ & 72 & $61(84.7)$ & $22(30.6)$ & $39(54.2)$ & 22 & $6(27.3)$ & 6 & $2(33.3)$ \\
\hline $60-69$ & 87 & $76(87.4)$ & $44(50.6)$ & $32(36.8)$ & 44 & $15(34.1)$ & 15 & $6(40.0)$ \\
\hline$\geq 70$ & 59 & $50(84.7)$ & $23(39.0)$ & $27(45.8)$ & 23 & II (47.8) & II & I (9.I) \\
\hline$P$-value & & 0.0001 & 0.0001 & 0.258 & & 0.153 & & 0.304 \\
\hline \multicolumn{9}{|l|}{ Sex } \\
\hline Male & 163 & I I 8 (72.4) & $48(29.4)$ & $70(42.9)$ & 48 & $19(39.6)$ & 19 & $7(36.8)$ \\
\hline Female & 181 & I5I (83.4) & $68(37.6)$ & $83(45.9)$ & 68 & $17(25.0)$ & 17 & $2(11.8)$ \\
\hline$P$-value & & 0.013 & 0.112 & 0.587 & & 0.095 & & 0.083 \\
\hline \multicolumn{9}{|l|}{ Diabetes } \\
\hline \multicolumn{9}{|c|}{ Age class (years) } \\
\hline$<40$ & 59 & $2(3.4)$ & I (I.7) & I (I.7) & 1 & - & - & - \\
\hline $40-49$ & 67 & $3(4.5)$ & $2(3.0)$ & I (I.5) & 2 & - & - & - \\
\hline $50-59$ & 72 & $5(6.9)$ & $3(4.2)$ & $2(2.8)$ & 3 & $3(100.0)$ & & $3(100.0)$ \\
\hline $60-69$ & 87 & II (I2.6) & $7(8.0)$ & $4(4.6)$ & 7 & 5 (7I.4) & & $2(40.0)$ \\
\hline$\geq 70$ & 59 & 7 (II.9) & $3(5.1)$ & $4(6.8)$ & 3 & $2(66.7)$ & & I (50.0) \\
\hline$P$-value & & 0.160 & 0.419 & $0.45 I$ & & 0.133 & & 0.233 \\
\hline \multicolumn{9}{|l|}{ Sex } \\
\hline Male & 163 & $21(12.9)$ & $10(6.1)$ & II (6.7) & 10 & $7(70.0)$ & 7 & 5 (7I.4) \\
\hline Female & 181 & 7 (3.9) & $6(3.3)$ & I (0.6) & 6 & $3(50.0)$ & 3 & I (33.3) \\
\hline$P$-value & & 0.002 & 0.215 & 0.002 & & 0.424 & & 0.260 \\
\hline
\end{tabular}

Notes: Data are reported as absolute values and percentages, in brackets. $P$-values refer to the statistical significance of the difference across ages (trend analysis) and between sexes.

developed countries and these chronic conditions have been associated with cardiovascular disease. ${ }^{1,8,9}$ It is currently estimated that in a few years ischemic heart disease and cerebrovascular disease will become the leading cause of the global health burden and a major social problem, both in terms of disability-adjusted life years and increased national health expenditures. ${ }^{24,25}$ Thus, early identification and adequate treatment of cardiovascular risk factors is important in order to reduce the risk of major cardiovascular disease.

Our study was carried out in a relatively small population living in a highly developed and wealthy area of Northern Italy, devised to evaluate the prevalence, awareness, and control of major cardiovascular risk factors in an unselected sample of individuals. Surprisingly, we found that high blood pressure, high serum cholesterol, diabetes, and obesity, are still highly prevalent and their control appears still largely unsuccessful, because of both poor patient awareness and lack of pharmacological treatment. Hypercholesterolemia and hypertension were among the most common risk factors for cardiovascular disease, recorded in $78 \%$ and $51 \%$ of subjects, respectively. Interestingly, central obesity, determined by measuring waist circumference, ranked high, with a prevalence of $61 \%$, a percentage much larger than obesity assessed by calculating body mass index (10\%). Overweight and impaired fasting glucose, two often underreported risk factors, ${ }^{1,11,19,21}$ were recorded in $36 \%$ and $23 \%$ of participants, respectively. As expected, diabetes affected a lower proportion of subjects (8\%). Our findings are consistent with and add to those observed in larger 


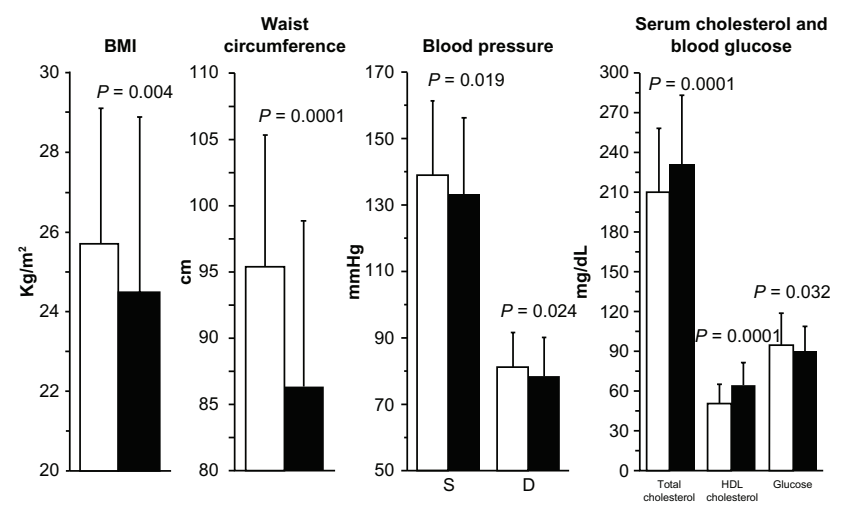

Figure 4 Mean values \pm SD for BMI, waist circumference, $S$ and D blood pressure, total and HDL serum cholesterol, and blood glucose in the 344 subjects of the study according to sex.

Notes: Males: open bars; females: full bars. $P$-values indicate the level of statistical significance of between-sex differences.

Abbreviations: BMI, body mass index; D, diastolic; HDL, high density lipoprotein; S, systolic; SD, standard deviation.

studies performed in Italy, with some variability according to the area of the country. ${ }^{26-35}$ These also confirm results from European ${ }^{9,36}$ and North American studies. ${ }^{37-41}$

One of the most interesting results of our study relates to the poor awareness, treatment, and control of cardiovascular risk factors. First, only approximately $50 \%-60 \%$ of the examined subjects were aware of their elevated total serum cholesterol, high blood pressure, or diabetes, while in the rest of the sample these conditions remained undiagnosed. Second, most of the hypertensive (90\%) and diabetic subjects $(60 \%)$ were pharmacologically treated, while only $30 \%$ of subjects with elevated total cholesterol reported using cholesterol lowering medications. Third, the majority of participants were not suitably treated for their specific cardiovascular risk factor. Specifically, blood pressure values were $<140 / 90 \mathrm{mmHg}$ and total serum cholesterol $\leq 190 \mathrm{mg} / \mathrm{dL}$ in $30 \%$ and $25 \%$ of treated subjects, respectively. On the other hand, the proportion of diabetic subjects achieving target blood glucose levels (below $126 \mathrm{mg} / \mathrm{dL}$ ) was higher, and occurred in approximately $60 \%$ of treated subjects. Lack of adequate pharmacological treatment and control resulted in $15 \%$ of participants being at high or very high risk and $6 \%$ at high-moderate risk of a major cardiovascular event in the next 10 years.

Interestingly, our findings on awareness, treatment, and control of major cardiovascular risk factors are in line with those of large epidemiological studies performed in European countries and North America. In all of these studies, the examined subjects reported a disappointingly low knowledge of their own cardiovascular risk status and a completely inadequate achievement of the targets defined in the prevention guidelines. ${ }^{1,936-40}$
Some additional results of our study deserve to be discussed. First, increasing age was associated with a significantly augmented prevalence of most major cardiovascular risk factors, with the exception of diabetes, probably because of the very limited number of diabetics included in our sample. These results are in accordance with those of previous studies in Italian ${ }^{27,28,30,31,34}$ and North-American populations. ${ }^{37-41}$ Also, the proportion of subjects treated for arterial hypertension, dyslipidemia, or diabetes increased with age, but the chance of being controlled did not display a favorable trend. Again, overweight and central obesity showed a net increase with age, appearing as a relevantly prevalent phenomenon associated with aging. ${ }^{34,39}$

Second, prevalence of cardiovascular risk factors was similar between males and females, with the exception of hypercholesterolemia and obesity, which were more prevalent in females, and diabetes and overweight, which were more prevalent in males, confirming evidence from previous large scale epidemiological studies. ${ }^{27,31,40}$

\section{Study limitations}

We acknowledge that our study has some limitations, primarily related to its study design. First, we recruited subjects through health centers, and thus the chance that participants in our survey come from a selected population is high, and we cannot exclude that respondents to our survey were particularly motivated to participate in the screening program, as they were already aware of their condition. Likely, a more random recruitment process could have been resulted in lower awareness or lower rate of previously diagnosed subjects. This might be the case particularly for hypertension, because almost the majority of hypertensive and diabetic patients were treated. However, on the other hand, only $20 \%$ of the subjects had a personal history of cardiovascular disease and approximately half of the subjects had no specific knowledge of their cardiovascular status, so our study is well balanced and may be appropriately defined as a prevalent primary prevention screening campaign. Second, data included in the analysis were collected in a relatively narrow and selected area of the country and on a relatively small sample of individuals. We acknowledge that the sample may not reflect the overall situation of the country and conclusions regarding the prevalence, treatment, and control may not be generalized or extended to other populations with a different risk profile. Notably, our results were not much different from those observed in larger samples of the Italian population. ${ }^{26-35}$ Third, finger-prick cholesterol and glucose tests have been reported to provide potentially unreliable results. ${ }^{42-44}$ However, the device used 
in our study has been validated against clinical diagnostic laboratory methods and proven to perform acceptably, providing health care professionals a rapid point of care method for lipid measurement. ${ }^{20,45}$ Finally, we were unable to get a complete blood lipid profile, because we could not measure serum triglycerides, and thus we could not derive LDL cholesterol or check the prevalence of metabolic syndrome, which might have helped to better define the cardiovascular risk profile of the screened subjects.

\section{Conclusion}

Our small-scale study indicates that major cardiovascular risk factors are highly prevalent in a wealthy general population of Northern Italy. The poor awareness of these conditions, the failure to start appropriate treatment, and lack of effective control of such risk factors suggest that more effective and comprehensive actions to detect, treat, and control patients at risk of cardiovascular events should be promptly undertaken. Whether our finding is a consequence of patients' unwillingness, physician inertia, or bureaucratic difficulties inherent to the health care system remains to be clarified. However, our study clearly demonstrates that population screening campaigns may represent simple and relatively inexpensive measures that may contribute to ameliorate cardiovascular risk detection, which is a first step for effective prevention of cardiovascular diseases. Effective public health measures and strategies are needed to improve prevention, diagnosis, and access to treatment for the general population at risk of cardiovascular events.

\section{Acknowledgments}

We are grateful for the logistic support provided by the volunteers of the Italian Red Cross of Gallarate and Monza, and by the Municipality of Monza. We also wish to thank Exxe Ltd, and Intermed Ltd, for providing the finger blood test analyzer, the professional scale, and the upper arm blood pressure monitors used in the study.

\section{Disclosure}

The authors report no conflicts of interest in this work.

\section{References}

1. Ezzati M, Lopez AD, Rodgers A, Vander Hoorn S, Murray CJ; Comparative Risk Assessment Collaborating Group. Selected major risk factors and global and regional burden of disease. Lancet. 2002; 360(9343):1347-1360.

2. Yusuf S, Hawken S, Ounpuu S, et al; INTERHEART Study Investigators. Effect of potentially modifiable risk factors associated with myocardial infarction in 52 countries (the INTERHEART study): case-control study. Lancet. 2004;364(9438):937-952.
3. Sans S, Kesteloot H, Kromhout D. The burden of cardiovascular diseases mortality in Europe. Task Force of the European Society of Cardiology on Cardiovascular Mortality and Morbidity Statistics in Europe. Eur Heart J. 1997;18(8):1231-1248.

4. Ergin A, Muntner P, Sherwin R, He J. Secular trends in cardiovascular disease mortality, incidence, and case fatality rates in adults in the United States. Am J Med. 2004;117(4):219-227.

5. Kubo M, Kiyohara Y, Kato I, et al. Trends in the incidence, mortality, and survival rate of cardiovascular disease in a Japanese community: the Hisayama study. Stroke. 2003;34(10):2349-2354.

6. Kesteloot H, Sans S, Kromhout D. Dynamics of cardiovascular and all-cause mortality in Western and Eastern Europe between 1970 and 2000. Eur Heart J. 2006;27(1):107-113.

7. Lopez-Jimenez F, Batsis JA, Roger VL, Brekke L, Ting HH, Somers VK. Trends in 10-year predicted risk of cardiovascular disease in the United States, 1976 to 2004. Circ Cardiovasc Qual Outcomes. 2009;2(5):443-450.

8. Tanuseputro P, Manuel DG, Leung M, Nguyen K, Johansen H; Canadian Cardiovascular Outcomes Research Team. Risk factors for cardiovascular disease in Canada. Can J Cardiol. 2003;19(11):1249-1259.

9. Kotseva K, Wood D, De Backer G, et al; EUROASPIRE Study Group. EUROASPIRE III. Management of cardiovascular risk factors in asymptomatic high-risk patients in general practice: cross-sectional survey in 12 European countries. Eur J Cardiovasc Prev Rehabil. 2010;17(5):530-540.

10. Kones R. Is prevention a fantasy, or the future of medicine? A panoramic view of recent data, status, and direction in cardiovascular prevention. Ther Adv Cardiovasc Dis. 2011;5(1):61-81.

11. Yang Q, Cogswell ME, Flanders WD, et al. Trends in cardiovascular health metrics and associations with all-cause and CVD mortality among US adults. JAMA. 2012;307(12):1273-1283.

12. Cooper R, Cutler J, Desvigne-Nickens P, et al. Trends and disparities in coronary heart disease, stroke, and other cardiovascular diseases in the United States: findings of the national conference on cardiovascular disease prevention. Circulation. 2000;102(25):3137-3147.

13. Yusuf S, Reddy S, Ounpuu S, Anand S. Global burden of cardiovascular diseases: Part II: variations in cardiovascular disease by specific ethnic groups and geographic regions and prevention strategies. Circulation. 2001;104(23):2855-2864.

14. National Health and Nutrition Examination Survey (NHANES). Anthropometry Procedures Manual. Hyattsville: Centers for Disease Control and Prevention; 2009. Available from: http://www.cdc.gov/nchs/data/ nhanes/nhanes_09_10/BodyMeasures_09.pdf. Accessed March 19, 2013.

15. National Institutes of Health. The Practical Guide to the Identification, Evaluation and Treatment of Overweight and Obesity in Adults. Bethesda: National Institutes of Health; 2000. Accessed March 19, 2013.

16. Alberti KG, Zimmet P, Shaw J; IDF Epidemiology Task Force Consensus Group. The metabolic syndrome - a new worldwide definition. Lancet. 2005;366(9491):1059-1062.

17. Parati G, Omboni S, Palatini P, et al. Italian society of hypertension guidelines for conventional and automated blood pressure measurement in the office, at home and over 24 hours. High Blood Press Cardiovasc Prev. 2008;15(4):283-310.

18. Longo D, Toffanin G, Garbelotto R, Zaetta V, Businaro L, Palatini P. Performance of the UA-787 oscillometric blood pressure monitor according to the European Society of Hypertension protocol. Blood Press Monit. 2003;8(2):91-95.

19. Mancia G, De Backer G, Dominiczak A, et al; The task force for the management of arterial hypertension of the European Society of Hypertension; The task force for the management of arterial hypertension of the European Society of Cardiology. 2007 Guidelines for the management of arterial Hypertension: The Task Force for the Management of Arterial Hypertension of the European Society of Hypertension (ESH) and of the European Society of Cardiology (ESC). Eur Heart J. 2007;28(12):1462-1536. 
20. Panz VR, Raal FJ, Paiker J, Immelman R, Miles H. Performance of the CardioChek PA and Cholestech LDX point-of-care analysers compared to clinical diagnostic laboratory methods for the measurement of lipids. Cardiovasc J S Afr. 2005;16(2):112-117.

21. American Diabetes Association. Standards of medical care in diabetes 2011. Diabetes Care. 2011;34(Suppl 1):S11-S61.

22. Palmieri L, Panico S, Vanuzzo D, et al; Gruppo di Ricerca del Progetto CUORE. Evaluation of the global cardiovascular absolute risk: the Progetto CUORE individual score. Ann Ist Super Sanita. 2004;40(4):393-399. Italian.

23. Ferrario M, Chiodini P, Chambless LE, et al; CUORE Project Research Group. Prediction of coronary events in a low incidence population. Assessing accuracy of the CUORE Cohort Study prediction equation. Int J Epidemiol. 2005;34(2):413-421.

24. Heidenreich PA, Trogdon JG, Khavjou OA, et al; American Heart Association Advocacy Coordinating Committee; Stroke Council; Council on Cardiovascular Radiology and Intervention; Council on Clinical Cardiology; Council on Epidemiology and Prevention; Council on Arteriosclerosis; Thrombosis and Vascular Biology; Council on Cardiopulmonary; Critical Care; Perioperative and Resuscitation; Council on Cardiovascular Nursing; Council on the Kidney in Cardiovascular Disease; Council on Cardiovascular Surgery and Anesthesia, and Interdisciplinary Council on Quality of Care and Outcomes Research. Forecasting the future of cardiovascular disease in the United States: a policy statement from the American Heart Association. Circulation. 2011;123(8):933-944.

25. Mathers CD, Loncar D. Projections of global mortality and burden of disease from 2002 to 2030. PLoS Med. 2006;3(11):e442.

26. Celentano A, Panico S, Palmieri V, et al. Citizens and family doctors facing awareness and management of traditional cardiovascular risk factors: results from the Global Cardiovascular Risk Reduction Project (Help Your Heart Stay Young Study). Nutr Metab Cardiovasc Dis. 2003;13(4):211-217.

27. Laccetti R, Pota A, Stranges S, et al. Evidence on the prevalence and geographic distribution of major cardiovascular risk factors in Italy. Public Health Nutr. 2013;16(2):305-315.

28. Tocci G, Rosei EA, Ambrosioni E, et al. Blood pressure control in Italy: analysis of clinical data from 2005-2011 surveys on hypertension. J Hypertens. 2012;30(6):1065-1074.

29. Grassi G, Arenare F, Dell'oro R, et al. Prevalence of cardiovascular risk factors in an unselected italian population. Results of the Cardiolab Project 2004-2008. Acta Cardiol. 2009;64(6):771-778.

30. Monesi L, Baviera M, Marzona I, et al. Prevalence, incidence and mortality of diagnosed diabetes: evidence from an Italian populationbased study. Diabet Med. 2012;29(3):385-392.

31. Donfrancesco C, Lo Noce C, Brignoli O, et al. Italian network for obesity and cardiovascular disease surveillance: a pilot project. $B M C$ Fam Pract. 2008;9:53.
32. Volpe M, Tocci G, Trimarco B, et al. Blood pressure control in Italy: results of recent surveys on hypertension. J Hypertens. 2007;25(7): 1491-1498.

33. Mancia G, Parati G, Borghi C, et al; SMOOTH investigators. Hypertension prevalence, awareness, control and association with metabolic abnormalities in the San Marino population: the SMOOTH study. J Hypertens. 2006;24(5):837-843.

34. Barbagallo CM, Cavera G, Sapienza M, et al. Prevalence of overweight and obesity in a rural southern Italy population and relationships with total and cardiovascular mortality: the Ventimiglia di Sicilia project. Int J Obes Relat Metab Disord. 2001;25(2):185-190.

35. Menotti A, Lanti M, Zanchetti A, et al. Impact of the Gubbio population study on community control of blood pressure and hypertension. Gubbio Study Research Group. J Hypertens. 2001;19(5):843-850.

36. Wolf-Maier K, Cooper RS, Kramer H, et al. Hypertension treatment and control in five European countries, Canada, and the United States. Hypertension. 2004;43(1):10-17.

37. Egan BM, Zhao Y, Axon RN. US trends in prevalence, awareness, treatment, and control of hypertension, 1988-2008. JAMA. 2010;303(20) 2043-2050.

38. Ford ES, Mokdad AH, Giles WH, Mensah GA. Serum total cholesterol concentrations and awareness, treatment, and control of hypercholesterolemia among US adults: findings from the National Health and Nutrition Examination Survey, 1999 to 2000. Circulation. 2003;107(17) 2185-2189.

39. Mokdad AH, Ford ES, Bowman BA, et al. Prevalence of obesity, diabetes, and obesity-related health risk factors, 2001. JAMA. 2003; 289(1):76-79.

40. Cowie CC, Rust KF, Byrd-Holt DD, et al. Prevalence of diabetes and impaired fasting glucose in adults in the US population: National Health And Nutrition Examination Survey 1999-2002. Diabetes Care. 2006;29(6):1263-1268.

41. Flegal KM, Carroll MD, Ogden CL, Curtin LR. Prevalence and trends in obesity among US adults, 1999-2008. JAMA. 2010;303(3):235-241.

42. Ciudin A, Hernandez C, Simo R. Non-invasive methods of glucose measurement: current status and future perspectives. Curr Diabetes Rev. 2012;8(1):48-54.

43. Naito HK, Kwak YS. Accurate measurement of serum total cholesterol: the need for standardization. J Am Coll Nutr. 1992;11 Suppl:8S-15S.

44. Boerma GJ. The quality of cholesterol tests from finger prick blood with physicians' office equipment. The need for rigid quality control and proper interaction. J Int Fed Clin Chem. 1991;3(4):154-159.

45. Dale RA, Jensen LH, Krantz MJ. Comparison of two point-of-care lipid analyzers for use in global cardiovascular risk assessments. Ann Pharmacother. 2008;42(5):633-639.
Vascular Health and Risk Management

\section{Publish your work in this journal}

Vascular Health and Risk Management is an international, peerreviewed journal of therapeutics and risk management, focusing on concise rapid reporting of clinical studies on the processes involved in the maintenance of vascular health; the monitoring, prevention and treatment of vascular disease and its sequelae; and the involvement of

\section{Dovepress}

metabolic disorders, particularly diabetes. This journal is indexed on PubMed Central and MedLine. The manuscript management system is completely online and includes a very quick and fair peer-review system, which is all easy to use. Visit http://www.dovepress.com/ testimonials.php to read real quotes from published authors. 